US Army Corps

of Engineers $S_{\circledast}$

Engineer Research and

Development Center

\title{
Modeling RF Noise in Urban Environments with Spatially Distributed Point Sources
}

Caitlin E. Haedrich and Daniel J. Breton

August 2020

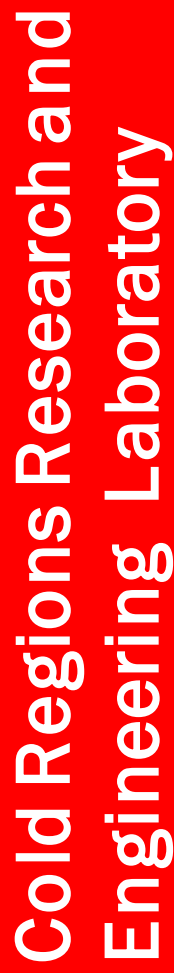


The U.S. Army Engineer Research and Development Center (ERDC) solves the nation's toughest engineering and environmental challenges. ERDC develops innovative solutions in civil and military engineering, geospatial sciences, water resources, and environmental sciences for the Army, the Department of Defense, civilian agencies, and our nation's public good. Find out more at www.erdc.usace.army.mil.

To search for other technical reports published by ERDC, visit the ERDC online library at https://erdclibrary.on.worldcat.org/discovery. 


\section{Modeling RF Noise in Urban Environments with Spatially Distributed Point Sources}

Caitlin E. Haedrich and Daniel J. Breton

Cold Regions Research and Engineering Laboratory

U.S. Army Engineer Research and Development Center

72 Lyme Road

Hanover, NH 03712

Final report

Approved for public release; distribution is unlimited.

Prepared for U.S. Army Corps of Engineers

Washington, DC 20314

Under Program Element 0611102T, Project Number T442, and Task Number 01 


\section{Preface}

This study was conducted for the U.S. Army Corps of Engineers under Program Element 0611102T, Project T442, and Task Number 01. The Technical monitor was Dr. Marino A. Niccolai.

The work was performed by the Signature Physics Branch of the Research and Engineering Division, U.S. Army Engineer Research and Development Center, Cold Regions Research and Engineering Laboratory (ERDCCRREL). At the time of publication of this Miscellaneous Paper, Mr. Dr. Marino A. Niccolai was Branch Chief; Mr. James Horne was Division Chief; and Dr. Robert Davis was the Technical Director for Geospatial Research and Engineering. The Deputy Director of ERDC-CRREL was Mr. David B. Ringelberg, and the Director was Dr. Joseph L. Corriveau.

This paper was originally published in proceedings of the North American Radio Science Meeting, July 5-10, 2020 in Montréal, Quebec, Canada. Funding was provided by the US Army Basic Research Program.

The Commander of ERDC was COL Teresa A. Schlosser and the Director was Dr. David W. Pittman. 


\section{Modeling RF Noise in Urban Environments with Spatially Distributed Point Sources}

\begin{abstract}
In previous work, we have observed significant variability in radio-frequency ( $R F$ ) noise within neighborhoods of Boston, MA, USA [1]. Furthermore, the sources of this man-made RF noise appear to be point-like in nature [2]. However, there are no descriptions in the literature describing the relationship between the spatial pattern of sources within a neighborhood and the distribution of measured noise powers in the same area. Therefore, we developed a simple model with completely spatially random (CSR) point sources and compared the modeled results with our measurements from Boston. Our results show that, at the frequency studied, a simple CSR model effectively captures the heavy-tailed behavior present in our measurements. A source density of 280 sources per $\mathrm{km}^{2}$, a mean source power of $1 \mu \mathrm{W}$ and a standard deviation of $7 \mathrm{~dB}$ are a reasonable match to the observed distribution in Boston, MA, USA.
\end{abstract}

\section{INTRODUCTION}

Radio-frequency (RF) noise is of interest because it effects the performance of sensitive electromagnetic devices. In urban environments, RF noise is dominated by man-made noise which is produced by many electrical and electronic devices [4]. Our current understanding of the urban noise field is largely built on stationary measurements ([5], [6] among others) resulting in a limited understanding of the spatial variability of noise. To address this gap in the literature, the Cold Regions Research and Engineering Laboratory (CRREL) has built a mobile RF noise measurement system detailed in [3]. In previous work, we have shown RF noise levels vary significantly throughout a neighborhood as shown in Figure 1. Furthermore, the analysis also showed that the urban noise field features point-like sources [2].

In this paper, we leverage our previous work to develop a model of completely spatially random (CSR) point sources [7]. The model assumes CSR "intensity" or likelihood of a point source occurring at a given location is spatially constant and the point source powers are normally distributed (in $\mathrm{dB}$ ) with a uniform mean throughout the environment. Through comparison with our measurements in Boston, we show that this simple model captures the heavy, high-powered tail we see in our measurements and can yield insight into the density and power of RF noise sources in Boston.

\section{Methods}

\section{A. Boston Measurements}

We conducted a measurement campaign in downtown Boston, MA, USA on July $17^{\text {th }}, 2019$, during normal business

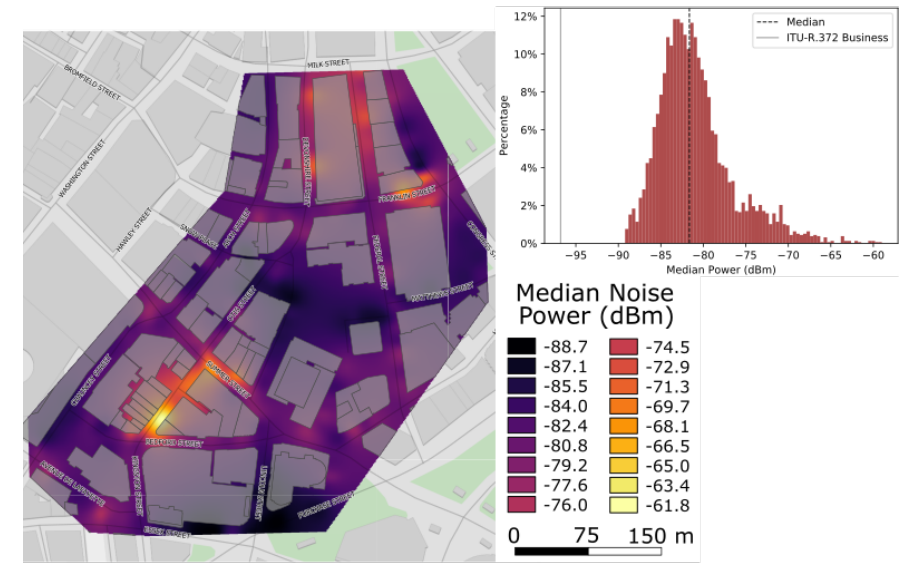

Fig. 1. Splined map of RF noise in downtown Boston (bottom) and a histogram of all the measurement collected throughout downtown (top). Data was collected July 2018. (Background map: (c) OpenStreetMap.)

hours (9AM to 5PM) [2]. Measurements were collected every meter along each street and walkable-alleyway over a 0.15 $\mathrm{km}^{2}$ section of downtown. Our measurement system, detailed in [3], recorded a $250 \mathrm{~ms}$ sample of In-Phase and Quadrature data in a $1 \mathrm{MHz}$ effective bandwidth centered on $142 \mathrm{MHz}$, an unused, federally exclusive portion of the spectrum. Following [4] and [6], we use the median power as a summarizing statistic for each $250 \mathrm{~ms}$ recording. Because spatial patterns in median noise power are temporally consistent in downtown Boston [1], we considered one survey sufficient to describe the spatial variability of noise power.

From our point data, we created splined maps of median power. To reduce the impact of temporal variations and smooth data, we grouped measurements in 10-meter segments before finding the median and splining. We used the QGIS GRASS v.surf.bspline tool [8] with the bilinear interpolation algorithm, a step of 8 meters and an output pixel size of 1 meter. The resulting map is shown in Figure 1 along with a histogram of our 1-meter interval measurements.

\section{B. Synthetic Noise Field Generation}

We developed a model for median noise power using CSR noise sources with the following assumptions:

1) Urban noise sources behave like point-sources 
2) These point sources are distributed in the environment according to CSR at a user-set density (sources per $\mathrm{km}^{2}$ )

3) Point source powers are normally distributed in decibels. The mean and standard deviation are user-set.

4) Noise propagates with free-space path losses (i.e. attenuation due to the built environment is unimportant)

\section{Monte Carlo Simulation}

To compare the model with our measurements, we use a Monte Carlo (MC) analysis described in [7]. We estimated our source density using the map in Figure 1 then ran the model 100 times. We created a cumulative distribution function (CDF) for each runs then saved the bounding CDFs to create an envelope of model outputs. The envelope is intended to capture a reasonable sample of possible CDFs based on different realizations of the CSR spatial and source power processes.

\section{RESUlTS}

Our measurements in Boston showed the presence of pointlike sources, distributed in space, giving rise to a heavy-tailed distribution of noise power. The MC model reproduces the observed heavy-tailed behavior for a wide variety of source densities. Figure 2 shows an example of the simple CSR model run with a source density of 300 sources per $\mathrm{km}^{2}$, a median source power of $1 \mu \mathrm{W}$ and a standard deviation of $7 \mathrm{~dB}$.

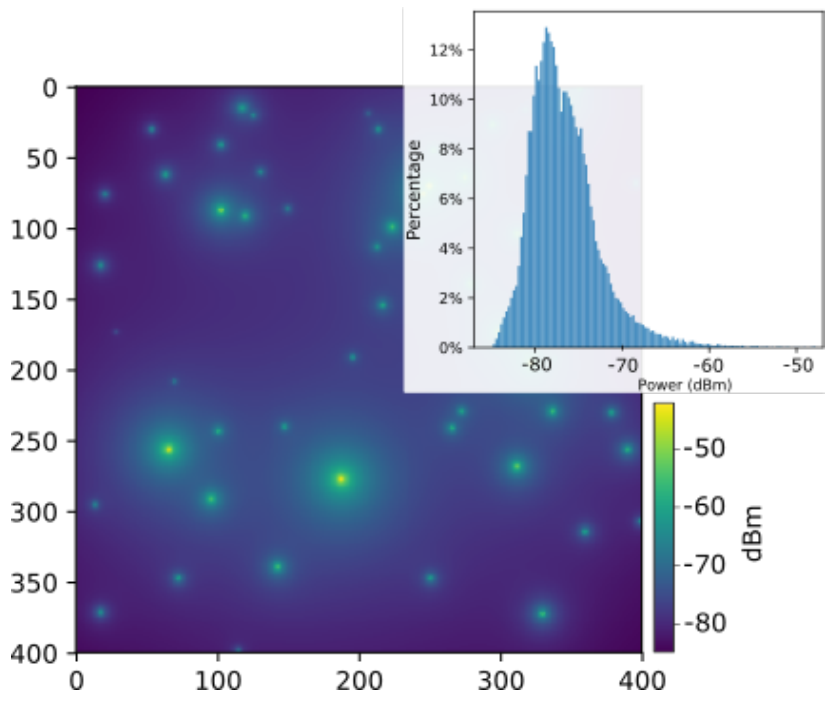

Fig. 2. An example output from a the CSR point model. The noise field was generated with a source density of 300 sources per $\mathrm{km}^{2}$ and a source power median of $1 \mu \mathrm{W}$ and a standard deviation of $7 \mathrm{~dB}$.

We estimated the measured point source density by assuming local maximums in Figure 1 indicate a point source nearby. The point source density in our survey area is about 280 sources per $\mathrm{km}^{2}$. Using 100 realizations of the CSR process at a source density of density of 280 sources per $\mathrm{km}^{2}$, we can see that the model reasonably captures the $\mathrm{CDF}$ behavior (Figure 3. The median of measured and MC models agree best with a median source power near $1 \mu \mathrm{W}$ and the tail behavior is best reproduced with a standard deviation of $7 \mathrm{~dB}$.

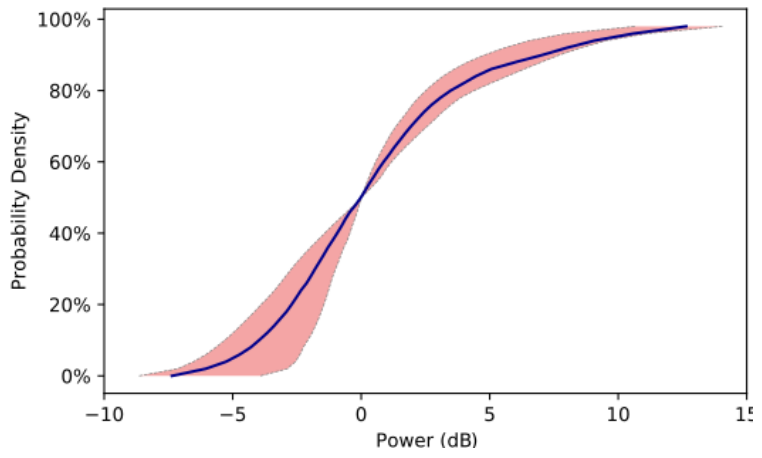

Fig. 3. Monte Carlo (MC) Simulation CDF Envelope (shaded red) with Boston data (blue line). The simulations were run with a source density of 280 source per $\mathrm{km}^{2}$ and a source power standard deviation of $7 \mathrm{~dB}$. The CDF envelope is created from the upper and lower bounds of 100 model runs.

\section{Discussion AND CONCLUSION}

The results demonstrate that, at $142 \mathrm{MHz}$, a simple CSR model can generate noise environments with similar CDFs to measurements from Boston, MA, USA. Furthermore, the model confirms that the density of point sources in downtown of about 280 sources per $\mathrm{km}^{2}$ and that the power of these point sources can be described by a normal distribution (in $\mathrm{dB}$ ) with a standard deviation of $7 \mathrm{~dB}$.

Further research is needed to understand and characterize the distribution observed in the model and in our measurements. Comparison of the model and measurements from other dense urban environments would also help generalize the behavior of RF noise in urban environment.

\section{ACKNOWLEDGEMENT}

Funding for this work was provided by the U.S. Army Basic Research Program. Permission to publish granted by Director, Cold Regions Research \& Engineering Laboratory.

\section{REFERENCES}

[1] D. Breton, C. Haedrich, M. Kamrath, D. K. Wilson, "Street-Scale Mapping of Urban Radio Frequency Noise at Very High Frequency and Ultra High Frequency", Radio Science Journal, vol. 54(11), pp. 934-948, 2019.

[2] C. Haedrich, D. Breton, D. K. Wilson, "Isarithmic mapping of radiofrequency noise in the urban environment", Military Sensing Symposia BAMS Committee Conference Proceedings, San Diego, CA, USA, October 21-24, 2019, unpublished.

[3] C. Haedrich, D. Breton, M. Kamrath, D. K. Wilson, "Measuring Very High Frequency and Ultrahigh Frequency Radio Noise in Urban Environments: A Mobile Measurement System for Radio-Frequency Noise", Report ERDC/CRREL TR-19-8, 2019.

[4] ITU. "ITU-R P.372: Radio Noise", International Telecommunications Union, Radiocommunications Sector, Geneva, CH. 2016.

[5] A. Spaulding and R. Disney, "Man-made radio noise, part 1: Estimates for business, residential and rural areas", U.S. Dept. Commerce, 1974.

[6] J. Wepman and G. Sanders. "Wideband Man-Made Radio Noise Measurements in the VHF and low UHF Bands", NTIA Tech. Rep. 2011.

[7] P. Diggle, "Statistical Analysis of Spatial Point Patterns." London, UK: Academic Press, 1983.

[8] GRASS Development Team. "GRASS GIS manual: v.surf.bspline." Open Source Geospatial Foundation, 2019. Retrieved from https://grass.osgeo.org/grass74/manuals/v.surf.bspline.html. 


\section{REPORT DOCUMENTATION PAGE}

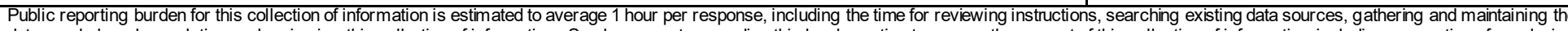

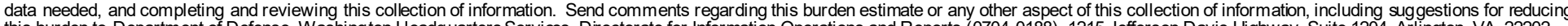

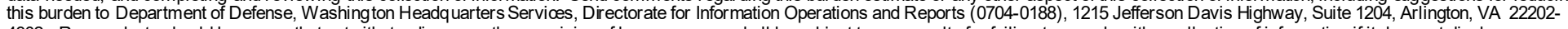

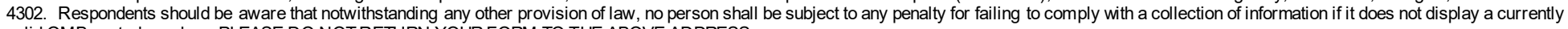
valid OMB control number. PLEASE DO NOT RETURN YOUR FORM TO THE ABOVE ADDRESS.
1. REPORT DATE
August 2020
2. REPORT TYPE
Final

4. TITLE AND SUBTITLE

3. DATES COVERED (From - To)

5a. CONTRACT NUMBER

Modeling RF Noise in Urban Environments with Spatially Distributed Point Sources

5b. GRANT NUMBER

5c. PROGRAM ELEMENT NUMBER

$0611102 \mathrm{~T}$

6. AUTHOR(S)

5d. PROJECT NUMBER

Caitlin E.Ha edrich and DanielJ. Breton

T442

5e. TASK NUMBER

01

5f. WORK UNIT NUMBER

7. PERFORMING ORGANIZATION NAME(S) AND ADDRESS(ES)

U.S. Army Engineer Research and Development Center

8. PERFORMING ORGANIZATION REPORT NUMBER

Cold Regions Research and Engineering Laboratory

72 Lyme Road

ERDC/CRREL MP-20-14

Hanover, NH 03755

9. SPONSORING / MONITORING AGENCY NAME(S) AND ADDRESS(ES)

10. SPONSOR/MONITOR'S ACRONYM(S)

U.S. Army Corps of Engineers

Washington, DC 20314-1000

USACE

11. SPONSOR/MONITOR'S REPORT NUMBER(S)

\section{DISTRIBUTION / AVAILABILITY STATEMENT}

Approved for public release; distribution is unlimited.

\section{SUPPLEMENTARY NOTES}

Originally published in proceedings of the North American Radio ScienceMeeting, July 5-10, 2020 in Montréal, Quebec, Ca nada. Funding was provided by the US Army Basic Research Program.

\section{ABSTRACT}

In previous work, we have observed significant variability in ra dio-frequency (RF) noise within neighborhoods of Boston, MA, USA. Furtherm ore, the sources of this man-made RF noise a ppear to be point-like in na ture. However, there are no descriptions in the litera ture describing the rela tionship between the spatial pattern of sources within a neighborhood a nd the distribution of measured noise powers in the sa me area. Therefore, we developed a simple model with completely spatially ra ndom (CSR)point sources and compared the modeled results with our measurements from Boston. Our results show that, at the frequency studied, a simple CSR model effectively captures the heavy-tailed behavior present in our measurements. A source density of 280 sources per km ${ }^{2}$, a mean source power of $1 \mu \mathrm{W}$ and a standard deviation of $7 \mathrm{~dB}$ are a reasonable match to the observed distribution in Boston, MA, USA.

\section{SUBJECT TERMS}

Radio frequency, Radio measurements, Noise, Spatial model

\begin{tabular}{|c|c|c|c|c|c|}
\hline 16. SECURITY CL & IFICATION OF: & & 17. LIMITATION & 18. NUMBER & 19a. NAME OF RESPONSIBLE PERSON \\
\hline $\begin{array}{l}\text { a. REPORT } \\
\text { Unclassified }\end{array}$ & $\begin{array}{l}\text { b. ABSTRACT } \\
\text { Uncla ssified }\end{array}$ & $\begin{array}{l}\text { c. THIS PAGE } \\
\text { Unclassified }\end{array}$ & UU & 5 & $\begin{array}{l}\text { 19b. TELEPHONE NUMBER } \\
\text { (include area code) }\end{array}$ \\
\hline
\end{tabular}

